\title{
Surfaces
}

\section{NO TIME LIKE THE PRESENT}

\section{Deborah Esch}

Volume 3, 1993

URI : https://id.erudit.org/iderudit/1065104ar

DOI : https://doi.org/10.7202/1065104ar

Aller au sommaire du numéro

Éditeur(s)

Les Presses de l’Université de Montréal

ISSN

1188-2492 (imprimé)

1200-5320 (numérique)

Découvrir la revue

Citer cet article

Esch, D. (1993). NO TIME LIKE THE PRESENT. Surfaces, 3. https://doi.org/10.7202/1065104ar
Résumé de l'article

L'auteure aborde l'analyse critique des médias télévisuels sous l'angle de la temporalité, et fait intervenir dans sa discussion les travaux de Cavell, de Man et Kernan sur les massmédias. 


\title{
NO TIME LIKE THE PRESENT
}

\author{
Deborah Esch
}

\section{ABSTRACT}

This essay approaches the question of the critical analysis of TV on the basis of the temporality of the televisual medium. Discussion of Cavell, de Man and Kernan on massmedia.

\section{RÉSUMÉ}

L'auteure aborde l'analyse critique des médias télévisuels sous l'angle de la temporalité, et fait intervenir dans sa discussion les travaux de Cavell, de Man et Kernan sur les massmédias.

As a point of departure, let me recall a passage from a recent essay entitled "Journals, Politics":

Many years ago -- it might already be twenty -- Max Horkheimer recommended a little experiment during a television interview. $\mathrm{He}$ suggested reading newspapers a few weeks or months after their 
publication. With this he bent over to pick up a stack of rather gray papers that lay next to his chair.

I cannot recall his comments on this piece of advice. But one can imagine that the effect he had in mind was supposed to be both philosophical and political. Indeed, the effect of this small postponement on the reader, on his perception of time and on his attitude to news and published opinion, should be considerable. The reader of these old papers will notice that the imperatives, attractions and threats heralded in them reveal themselves as such only to the degree that they no longer directly affect him. The judgments that the newspapers imposed on him at another time can now be dismissed as hectic presumptions. In the future he will no longer so easily obey the regulations of the newspapers and their time.... Horkheimer's is a piece of political advice that looks forward to the suspension of coercion and to its transformation for another way of life. (emphasis added)[1]

It is telling, I think, that this philosophically and politically instructive mise en scène took place "during a television interview," i.e. in the frame provided by what Virilio has termed the "third window." What I'd like to attempt in what follows is to bring the force of this experiment to bear in a very preliminary way on the specificity of television as a medium.

In reflecting on what distinguishes television from other media, I find myself returning time and again to the formulation provided by Gillian Skirrow and Stephen Heath in their early essay "Television: A World in Action": "What is specific to television-- the possibility of 'live broadcasting', the present electronic production of the image -- becomes the term of its exploited imaginary, the generalized fantasy...that is, that the image is direct, and direct for me... which fantasy is then taken for the ground reality of television and its programs.[2] What still recommends this analysis, which is by now nearly fifteen years old, is the remarkable economy with which it distinguishes two crucial components of the televisual imaginary that have come to be generalized -- that is, to be taken as the basis for a theory of television as medium, theory being the grounding of the interpretation and evaluation of the object in a general conceptual system.[3] Those components are:

-- first, the fantasy that the image is direct (i.e., that it functions as if it were not "produced," by way of a particular technics or technology of representation, but were somehow an unmediated, straightforward presentation, and, 
-- second, the concomitant fantasy that the image is direct for me (as if it were unproblematically addressed to me, presented to me, in a here and now that I share with the imaged event).

In categorical terms, what are at stake here are fundamental presuppositions about the relation between the order of perception and that of cognition, including the assumption that, especially where so-called "live" broadcasting is concerned, visibility translates as cognitive availability. Following Heath and Skirrow, Jane Feuer has elaborated a critique of the mechanism whereby the presumed ontology of television, defined in accordance with the possibility of the instantaneous recording, broadcasting and reception of the event, becomes (once again) generalized as a theory of television as medium. Accompanying that generalization (and recall that what is generalized is a fantasy, a highly seductive one) is an ideologization that it becomes crucial, for philosophical as well as political reasons, to resist. Such resistance begins with recalling the medium in its difference not only from other media, but from itself.[4]

When we forget the specificity of broadcast television in particular, what we forget is time. As Mary Ann Doane argues persuasively in her essay "Information, Crisis, Catastrophe," "Time is television's basis, its principle of structuration as well as its persistent reference. The insistence of the temporal attribute may indeed be a characteristic of all systems of imaging enabled by mechanical or electronic reproduction."[5] A recent instance brought this home, affording a reminder of what we are too liable to forget (and constituting, in effect, my own inadvertent experiment). Several seasons back, I was working on a preliminary version of this text as the Senate Judiciary Committee's hearings on the confirmation of Clarence Thomas -- what ABC correspondent Jack Smith characterized as "perhaps the most riveting television since Watergate, or the McCarthy hearings"[6] -were broadcast "live" by the American networks (including CNN, which, you'll recall, became a full partner with the ABC, CBS and NBC during its saturation "coverage" of the Gulf War[7]). For the most part, I listened to the hearings on National Public Radio, with the TV monitor on, but the sound muted. At a certain point on the afternoon of October 12, 1991, I looked up from my draft and over at the other screen, and saw that the video image of the hearings bore a caption whose variants are so familiar to viewers of broadcast news: "NBC, Live 5:00 EDT." I then discerned that video and audio were out of synch, that the sound emerged from the radio in advance of the televised image that was nonetheless emphatically labelled "live."[8]

To return to the terms provided by Werner Hamacher in the citation with which I began: the "effect of this small postponement" -- not a matter of a few weeks or months, as in Horkheimer's proposed experiment with print journalism, but of less than a second -- the effect on my perception of time and on my attitude toward what I was seeing was indeed "considerable." The 
successive judgments imposed by the broadcast became recognizable, however fleetingly, as the hectic presumptions they were. Or rather, the crucial difference between judgment and presumption itself became readable, thinkable. Not by chance, the context was the unfolding of a drama, and specifically a trial scene, one that persisted in invoking the "truth" ("Only one of them is telling the truth," intoned senators and commentators alike; "What really happened between Anita Hill and Clarence Thomas?") but was, as trial scene, a sustained exercise in persuasion, a deployment of rhetoric for political interests and ends, and not for the sake of establishing the truth or the meaning of past and present events (this is not to suggest, with some of the right-wing members of the committee and the media, as well as Thomas himself, that Anita Hill was the tool or the dupe of interest groups; the assumption that she was indeed "telling the truth" about "what really happened" does not change the rhetorical status of the scene itself).

Predictably enough, the video images of the hearings were promptly noted, sorted and glossed in print. As a television critic for the Los Angeles Times observed, "Some of the pictures have conveyed self-contained dramas in themselves," among them the spectacle of "Senators on both sides quoting newspapers as automatic truth when it was in their best interests, then attacking newspapers when it wasn't."[9] We confront, then, the typically vicious circle in which newspapers quote TV quoting newspapers -- and whatever sense we can make of this will depend on the truth value accorded to these media in the first place. This returns us to what Doane, in the context of an analysis of disinformation as an abuse of broadcast television, calls the "automatic truth value associated with this mode of dissemination"(224), a truth value that is predicated in large part on our investments in so-called "live" television, generalized as a model and "then taken for the ground reality of television and its programs."

(Another indication of this "automatic truth value" was an item reported as part of the media response to Oliver Stone's controversial film JFK: namely, a poll taken many years after the Kennedy assassination disclosed that an overwhelming number ofAmericans -- at least as many as believe the Dallas events were part of a conspiracy -- were convinced that they had seen the assassination live on television, though the Zapruder film was in a vault at Time-Life until five years later, and only available as still photographs in the interim.[10] In this case, the "effect of [the] postponement" was again "considerable": it involved the belated substitution of the mediated image for the then and there of an event supremely associated with the failure of cognition.)

The unproblematic articulation of live TV with the real (and real time) has its impulse in a broader realist ideology that seeks its opportunity in the failure to reflect on the medium, on the distances of space and time that characterize its structure and effects.[11] A telling instance of this 
forgetting occurs in an essay by Stanley Cavell, symptomatically entitled "The Fact of Television," in which he posits "the material basis of television as a current of simultaneous event reception. "This, [he writes] is how I am conceiving of the aesthetic fact of television that I propose to begin portraying" (252).[12]/ pp. 10-11/

In interrogating the medium of television, Cavell returns to his earlier attempts, in The World Viewed, "to distinguish the fact of movies from the fact of theater, on the blatant ground that in a theater the actors appear in person and in a film they do not" (251). He recalls Andre Bazin's argument to the contrary (in What is Cinema?[13]) that film "relays the actors' presence to us as by mirrors." Cavell is then struck, after the fact, that"Bazin's idea here really fits the fact of live television, in which what we are presented with is happening simultaneously with its presentation. This [he concludes] remains reasonably blatant, anyway unsurprising" (252). What is perhaps surprising is Cavell's obliviousness to the temporal complexity not only of the medium, but of his own argumentation, which proceeds in large part by citing his own past formulations, preserving their syntax as he substitutes fresh terms supposed to correspond to the new instance, the new medium.

The characterization of "the material basis of television", the "aesthetic fact of television", as "a current of simultaneous event reception" is thus elaborated over against his earlier "provisional, summary characterization of the material basis of movies, apart from which there would be nothing to call a movie... I call the basis a succession of automatic world projections" (251, citing The World Viewed, 72). The multiple substitutions involved here ("current" and "simultaneous" for" succession" and "automatic," "event" for "world," "reception" for "projection") ground a further distinction: "The mode of perception that I claim is called upon by film's material basis is what I call viewing. The mode of perception I wish to think about in connection with television's material basis is that of monitoring" (252), which is to say "preparing our attention to be called upon by certain eventualities" -- monitoring "as in monitoring the heart, or the rapid eye movements during periods of dreaming -- say, monitoring signs of life" (258) -- for, as he takes the occasion to affirm, "where there's life, there's hope" (254). He goes on to acknowledge that his definition of television's material basis leaves out transmission and broadcasting as integral to television's operation, "as essential to [its] work,"and hence leaves out of account the complications these functions would introduce into his model.

Cavell, for whom the medium is "revealed" or "acknowledged" in the format, observes further about "the amount of talk that runs across" television's formats that "the frequent description of television as providing 'company'... is [partly] a function of the simultaneity of the medium -- or of the fact that at any time it might be live and that there is no sensuous distinction between the live and the repeat, or the replay: the others are there, if not 
shut in this room, still caught at this time. One is receiving them or monitoring them, like callers; and receiving or monitoring, unlike screening and projection, does not come between their presence to the camera and their presentness to us" (253). But if the medium's structure is not one of precise simultaneity, something does come between, and we find ourselves in the more disconcerting "company" of ghosts. Strictly speaking, television is never live: for, as Derrida has noted, "When the very first perception of an image is linked to a structure of reproduction, then we are dealing with the realm of phantoms."[14]

While Cavell designates this one-dimensional monitoring function the "aesthetic fact of television," his essay clearly puts forward a theory of the medium, based once again on a generalization of "live" broadcasting -- and the confusion of fact and theory, as well as the collapse of the distinction between the "aesthetic fact" and the "material basis," are themselves, I would suggest, effects of what Paul de Man has termed aesthetic ideology. I want to outline by way of conclusion what de Man's analysis of the aesthetic ideology might contribute to the possibility of reading television.

That analysis comprises, importantly, a sustained investigation of the values associated, at least since the eighteenth century, with symbolical and allegorical conceptions of language. In "The Rhetoric of Temporality," de Man interrogates the way in which "the supremacy of the symbol, conceived as an expression of unity between the representative and the semantic functions of language, becomes [in the nineteenth century] a commonplace that underlies literary taste, literary criticism, and literary history," as well as the extent to which it "still functions as the basis of recent French and English studies of the romantic and postromantic eras.[15] He argues that the symbol, a figure predicated on the presumed continuity and simultaneity of "the sensory image and the supersensory totality that the image suggests," in turn grounds an understanding of the subject-object relation "in which the experience of the object takes on the form of a perception or a sensation. The ultimate intent of the image is synthesis," he writes, and "the mode of this synthesis is defined as symbolic by the priority conferred on the initial moment of sensory perception" -- i.e., on the aesthetic moment. The symbol, then, proves to be the linguistic condition of possibility of a certain claim for the autonomy and the power of the aesthetic: the aesthetic ideology.

De Man's analysis demonstrates that the symbol, rather than being generalizable as a model of language, is "a special case of figural language in general, a special case that can lay no claim to historical or philosophical priority over other figures," including allegory (191). It is allegory that disrupts the possibility of the symbolic synthesis by opening up a constitutive temporal dimension, the difference that divides the allegorical sign from the previous sign to which it refers. "The meaning constituted by the allegorical sign can then consist only in the repetition... of a previous 
sign with which it can never coincide, since it is of the essence of this previous sign to be pure anteriority. Whereas the symbol postulates the possibility of an identity or identification, allegory designates primarily a distance in relation to its own origin, and, renouncing the nostalgia and the desire to coincide, it establishes its language in the void of this temporal difference" (207). Allegory confesses the failure of coincidence forgotten or repressed in the symbol, in which the relationship of image and substance, image and event, is taken to be "one of simultaneity, which, in truth, is spatial in kind, and in which the intervention of time is merely a matter of contingency" (207).

In its detail and its scope, this analysis effects a radical revision of conventional literary--historical and aesthetic categories, disrupting the rhetoric and the ideology of the symbol, with its values of continuity, organicity, homogeneity, symmetry and totality. If we read de Man's critique of the aesthetic ideology into one recent lament for the decline of print and the ascendancy of electronic media, we may at least adumbrate its potential for understanding the differential specificity of television. In his essay "The Death of Literature," which summarizes the argument of his book of the same title, Alvin Kernan warns that "in an age in which television, not books, will define the realm of knowledge, the concept of literature could easily disappear. Television is not symbiotic with literature the way that print was. Literary values -- authors, great works, deep meanings -- fitted hand-in-glove with print, but television both weakens literacy (the skill on which literature depends) and undercuts literature's basic functions. The replacement of the printed word by the image and the voice substitutes immediate, powerful one-dimensional pictures and simple continuities for the ironies, ambiguities, and complex structures fostered by print and idealized in literature.[16] For Kernan, then, aesthetic values are not only compatible with the complex linguistic structures "fostered by print and idealized by literature" -- a compatibility de Man puts in serious question -- their relation is continuous, "symbiotic," "hand-in-glove." Hence his claim, his point of departure and point of return, that romantic and modern literature's "leading values were aesthetic versions of print logic."

Cavell's own starting point is "an effort to get at something one can see as the aesthetic interest of television. That there is such an interest invited by, related to, but different from, an interest in what we call its economy, its sociology, and its psychology, and that this interest is still insufficiently understood -- which contributes to an insufficiently developed critical tradition concerning television...is the point from which any contribution I may make to it is apt to proceed"(250-51). But what Cavell designates the "aesthetic fact of television" -- a current of simultaneous event reception -marks the point of convergence between the aesthetic ideology and an ideology of realism that "finds the final guarantee of reality in the power of so-called facts. This reality," as Hamacher insists, "is actually generated by all sorts of societal -- and not only societal -- institutions and all sorts of techniques -- among them techniques of language. Putting this realism into question [he argues], is an eminently political act, even if it is not articulated 
in explicitly political terms, but rather in linguistic and philological ones"(448).

It is in terms such as these, then, that we can understand Horkheimer's experiment with newspapers as philosophical as well as political in its effects. Hamacher glosses his recollection of the scene further:

Try to imagine what would happen if daily papers printed news and commentary of three and a half months ago today, if others printed that of fifteen years ago and still others that of 1941, of 1922. The effect would not be to blur past and present,but rather to make them more pronounced. After all, one of the dangerous effects of the chronological order in which newspapers appear is the numbing of the sense of what history, and what the present could be.

With the stakes thus demonstrably high, then, there is no time like the present for addressing the dangerous, even deadly consequences of the failure to reflect on the rhetorical, temporal and ideological conditions of the signals we mistakenly call "live."

\title{
Deborah Esch
}

\section{Department of English}

\author{
University of Toronto
}

Surface Page d'Acceuil/Home Page

[1]Werner Hamacher, "Journals, Politics" in Responses, ed. Hamacher, Neil Hertz and Thomas Keenan (Lincoln: University of Nebraska Press, 1988) 457.

[2]Stephen Heath and Gillian Skirrow, "Television: A World in Action," Screen 18;2 (Summer 1977). See also Jane Feuer, "The Concept of Live 
Television: Ontology as Ideology" in Regarding Television: Critical Approaches, ed. E. Ann Kaplan (Frederick, Md: University Publications of America, 1982) 12--22.

[3]This is (for example) Paul de Man's definition of theory in The Resistance to Theory (Minneapolis: University of Minnesota Press,1986) 5.

[4]Fredric Jameson distinguishes "three relatively distinct signals" in his analysis of the media, and specifically of video, which functions as mode of aesthetic production, as technology, and as social institution, in Postmodernism, or, the Cultural Logic of Late Capitalism (Durham: Duke University Press, 1991) 67.

[5]Mary Ann Doane, "Information, Crisis, Catastrophe" in Logics of Television: Essays in Cultural Criticism, ed. Patricia Mellencamp (Bloomington: University of Indiana Press, 1990) 222. Doane's gloss on Jane Feuer's "The Concept of Live Television" is suggestive for purposes of the present argument: "Although...television rarely exploits this technical capability [instantaneous recording, transmission and reception], minimizing not only 'live' transmission but preservation of 'real time' as well, the ideology of 'liveness' works to overcome the excessive fragmentation within television's flow. If television is indeed thought to be inherently 'live,' the impression of a unity of 'real time' is preserved, covering over the extreme discontinuity which is in fact typical of television in the U.S. at this historical moment" (227).

[6]ABC news coverage of the Thomas confirmation hearings, Sunday 13 October 1991.

[7]Stanley Cavell remarks parenthetically on the way in which"live [television's] point is not to reveal, but to cover (as with a gun), to keep something on view" ("The Fact of Television" in Themes Out of School: Effects and Causes (San Francisco: North Point Press, 1984) 252. The analogy between modes of coverage, I would suggest, is not accidental, as the example of the Gulf War made painfully clear. For a range of responses to television's role in that conflict, see the inaugural issue of Alphabet City on "Gulf War T.V." (Summer 1991).

[8]One could argue that a certain time lag was crucial to the proceedings themselves and their outcome, insofar as Anita Hill testified first, affording an interval for the consolidation of the logic, the strategy and the tactics used against her by Thomas and his supporters.

[9]Howard Rosenberg, "High Noon in Television's High Court," Los Angeles Times 14 October 1991, F10.

[10]A recent New York Times/CBS survey on the assassination reported that "Of those polled, 77\% said they believed that people besides Lee Harvey Oswald were involved in the killing. And 75 said there was an official coverup in the case" (New York Times 4 February 1992, B1).

[11]For an exemplary analysis of these distances, see Samuel Weber, "The Media and the War," Alphabet City 1;1:22-26. On the ways in which the 
ideology of "liveness" works to preserve the impression of "real time," see Doane (227) and Paul Virilio, L'ecran du desert: Chroniques de guerre (Paris: Galilée, 1991), esp. 77-82. Virilio argues that the rhetorical force of the"live" image reduces time to a fait accompli, something to which one simply submits.

[12]"The Fact of Television" was first published in a 1982 issue of Daedalus on "Print Culture and Video Culture," reprinted in 1984 in his Themes out of School, and again in the recent anthology Video Culture: A Critical Investigation, ed. John Hanhardt (Rochester: Visual Studies Workshop Press, 1986).

[13]Bazin, What is Cinema?, trans. Hugh Gray (Berkeley: University of California Press, 1967), 97.

[14]Andrew Payne and Mark Lewis, "The Ghost Dance: Interview with Jacques Derrida," Public 2 (1989) 61. Cf. Deborah Esch, "Mourning Television" in Surfaces 1.6 (Oct 1991).

[15]Paul de Man, "The Rhetoric of Temporality" in Blindness and Insight:

Essays in the Rhetoric of Contemporary Criticism, 2nd edition (Minneapolis: University of Minnesota Press, 1983) 189-90.

[16]Alvin Kernan, "The Death of Literature," Princeton Alumni Weekly 92;8 (January 22, 1992): 11-15. See also his The Death of Literature (New Haven: Yale University Press, 1990), esp. ch. 6. 